correct such assumptions. These therapeutic methods could be learnt by other therapists, and evaluated scientifically in follow-up studies.

Queen Mary's University Hospital

Paul Crichton

Roehampton Lane

London SWIS SPN

\section{Mental health legislation and the practice of psychiatry}

DeAr SIRS

The letter from Dr McNicholas (Psychiatric Bulletin, 1992, 16, 568-569) makes compelling reading. Her focus appears to be on the cost factors as primary predictors of treatment within the mental health arena, and indeed in some cases this is certainly the case. However, one factor which she failed to mention is the influence of mental health legislation upon the practice of psychiatry. Although not working in the United States, I can speak from a Canadian perspective. The changes that are occurring in mental health legislation here are primarily directed towards the rights of the individual. This is an excellent premise in many areas as it allows greater patient autonomy and a sense of involvement in the treatment process. However, psychotic patients may have very little insight into their disabilities, and they are in danger of avoiding the treatment they sorely need. This most vulnerable and disadvantaged section of the psychiatric population may actually be harmed by their own autonomy in such an instance, and it behoves physicians to advocate on behalf of such patients in an attempt to assure their right to treatment.

Dr McNicholas is correct in her suggestion that al patients should have appropriate care irrespective of cost. We must also attempt to insure that mental legislation is directed toward those most in need.

University of Alberta

Alan P. Byrne

Edmonton, Canada TG6 2B7

\section{Psychiatry of mental handicap - its future}

DeAr SIRS

Psychiatrists who work predominantly in mental handicap services are concerned about the development of services for those of their patients who also develop mental and emotional illness. The minority with joint contractual arrangements with general psychiatry and child psychiatric services may not feel anxious about this issue, but the majority of psychiatrists working in mental handicap do not seem to have a clear role or function in the new services. With the reorganisation of the NHS, particularly with the emergence of independent trusts of hospitals and community services, the confusion will, I am sure, turn into chaos.

Already in some areas, in order to get more 'business and finance", general psychiatric colleagues are willing to provide services for mentally handicapped patients with mental illness. If money can be saved by these means, such practices may be encouraged and the integration of psychiatric mental handicap services with general psychiatric services, child psychiatric services, etc, will accelerate.

The principles of normalisation could be manipulated to support such 'integration'. Local authority social services, who have the major responsibility for the provision of services for mentally handicapped people, may also use such cost-saving tactics. Conflict between psychiatric subspecialties arising from the change of policy by trusts will be detrimental to both specialist and general provision for mentally handicapped people and their families.

Does the psychiatry of mental handicap as a distinct subspecialty have a future? Will there be a gradual merger with general psychiatry and other subspecialties? This would certainly adversely affect the training and educational needs of the psychiatrists and ultimately the service for this vulnerable section of society. However, if there is going to be integration of specialised services within the core of general psychiatric services or other specialised services, then there is an urgent need to clarify the role, function and division of the expertise, that is, specialists, psychiatrists, specialist nurses, etc, within these emerging and developing integrated services.

The Royal College of Psychiatrists, particularly the mental handicap, general psychiatry, community psychiatry and child psychiatry sections, should urgently look at this issue and provide guidelines to the profession as well as service providers, and the government.

Hensol Hospital

T. HARI SINGH

Near Pontyclun CF78YS

\section{$M R I$ on adolescents presenting with schizophrenia}

\section{DeAr Sirs}

It can now be considered standard practice to undertake brain scanning of adolescents presenting with schizophrenia. Magnetic Resonance Imaging (MRI) offers the best available resolution and the least invasive method.

The chances of a brain scan producing results of immediate clinical relevance to the management of an individual patient are not high. However, we can expect quantitative differences between the brains of adolescents with schizophrenia and those of control 